Dr PETAR DRAGIŠIĆ, naučni saradnik Institut za noviju istoriju Srbije

\title{
JUGOSLAVIJA I AUSTRIJA 1945-1955. Rezime odnosa
}

\begin{abstract}
APSTRAKT: Članak predstavlja koncizan pregled odnosa Jugoslavije i Austrije u prvoj deceniji posle Drugog svetskog rata. Fokusiran je problem Koruške, koji je tokom prvih posleratnih godina onemogućavao približavanje dve zemlje. Analiziran je i proces postepene normalizacije jugoslovensko-austrijskih posle 1949. godine. Akcenat je stavljen na političko približavanje, na jačanje kulturnih i privrednih veza, kao i na promenu percepcija jednih o drugima u prvoj polovini 1950-ih godina.
\end{abstract}

Ključne reči: Jugoslavija, Austrija, Tito, Koruška, Slovenci

Okončanjem Drugog svetskog rata i radikalnim promenama koju su usledile u jugoistočnoj i srednjoj Evropi započela je nova epoha odnosa Jugoslavije i Austrije. U obe države kraj rata je označio početak drastičnih unutrašnjih promena. Dok je Austriji kraj rata doneo okupaciju od strane sila pobednica (Sovjetskog Saveza, Sjedinjenih Američkih Država, Velike Britanije i Francuske), u Jugoslaviji je posle komunističkog zauzimanja vlasti započeo proces temeljne transformacije društvenog i političkog sistema. Osim toga, kraj rata doveo je i do radikalne promene celokupnog spoljnopolitičkog konteksta, što je snažno uticalo na odnose Jugoslavije i Austrije u posleratnoj epohi.

Tokom prvih posleratnih godina odnosi dve države su bili zaoštreni, što je pre svega bilo izazvano teritorijalnim pretenzijama socijalističke Jugoslavije na delove Koruške, koje je jugoslovenski režim bazirao na postojanju slovenačke manjine u pomenutim oblastima. Jugoslavija je nastojala da prisajedinjenje delova Koruške izdejstvuje već u finalnoj fazi rata. Radilo se o očiglednoj nameri da se iskoristi haotično stanje u ovom delu Evrope i

* Rad je deo projekta Tradicija i transformacija - istorijsko nasleđe i nacionalni identiteti u Srbiji u 20. veku, (47019), koji finansira Ministarstvo prosvete, nauke i tehnološkog razvoja Republike Srbije. 
brzim potezima Austrija, kao i zapadni saveznici, stavi pred svršen čin. Pokušaj vojnog rešenja koruškog pitanja usledio je početkom maja 1945. Upad jedinica NOVJ na teritoriju Koruške poklopio se sa raspoređivanjem britanskih okupacionih snaga na tom delu austrijske teritorije. Jugoslovenske jedinice ušle su u Klagenfurt 8. maja 1945. U koruškoj prestonici već su se nalazile britanske trupe. ${ }^{1}$ Samo nekoliko dana kasnije Josip Broz Tito se suočio sa energičnim protestima zapadnih saveznika (Velike Britanije i Sjedinjenih Američkih Država), koji su zatražili povlačenje jugoslovenskih trupa iz okupiranih oblasti Koruške. Mesta za kompromis nije bilo, pa je već 19. maja započelo povlačenje jugoslovenskih jedinica iz Austrije. ${ }^{2}$ Povlačenjem jugoslovenskih trupa iz Austrije problem Koruške nije bio rešen, budući da jugoslovenska strana nije bila spremna da odustane od pretenzija na južne delove Austrije. U narednim godinama jugoslovenski režim se aktivno, na diplomatskom terenu, borio za prisajedinjenje delova Koruške Jugoslaviji, što je do početka 50-ih godina predstavljalo izvor stalnih tenzija u odnosima Jugoslavije i Austrije.

Neodustajanje jugoslovenskih vlasti od Koruške Josip Broz Tito je najavio ubrzo po neuspešnom okončanju jugoslovenske vojne operacije $u$ Austriji. Krajem maja 1945. jugoslovenski premijer je u govoru u Celju istakao da je Koruška "naša“ (jugoslovenska - P. D.), te da će se Jugosloveni boriti za Korušku. Mesec dana kasnije Tito je u razgovoru sa delegacijom AFŽ-a podvukao da Koruška nije zaboravljena i da će Jugoslavija učiniti sve da dođe do prisajedinjenja koruških Slovenaca Jugoslaviji. ${ }^{3}$

Jugoslovenske teritorijalne aspiracije prema Austriji pratila je i snažna propagandna kampanja jugoslovenskih štampanih medija. Najtiražniji jugoslovenski dnevnici su do početka 50 -ih godina oštro kritikovali politiku Austrije prema jugoslovenskim manjinskim grupama u toj zemlji, pre svega prema Slovencima u Koruškoj, ali i prema Hrvatima u Burgenlandu. Napadano je, između ostalog, sprovođenje odredbe o dvojezičkoj nastavi u koruškim školama. Pokušaj jugoslovenskog propagandnog aparata da dokaže postojanje represivne politike prema pomenutim etničkim zajednicama mogao je biti dvojako motivisan. Sa jedne strane, oštre kritike austrijske manjinske politike u Austriji trebalo je da mobilišu jugoslovensku javnost za vođenje diplomatskog rata za Korušku. Sa druge strane, može se pretpostaviti da se na taj način nastojalo da se međunarodnim faktorima koji su se tih godina bavili pitanjem austrijske budućnosti prezentuje jugoslovenska verzija položaja jugoslovenskih manjina u Austriji. Diskreditovanju Austrije

\footnotetext{
${ }^{1}$ Wilhelm Wadl, Das Jahr 1945 in Kärnten, Klagenfurt 1985, 32-42.

2 Documents on the Carinthian Question, Belgrad 1948, 40-42; Wilhelm Wadl, Das Jahr 1945 in Kärnten, 42.

${ }^{3}$ Josip Broz Tito, Sabrana djela, 28, Beograd 1988, 83, 115.
} 
trebalo je da posluže i brojni tekstovi u kojima je oštro kritikovano sprovođenje denacifikacije u Austriji, a posebno u Koruškoj. ${ }^{4}$

Poseban segment jugoslovenske propagandne kampanje protiv Austrije bilo je i podvlačenje austrijske odgovornosti za događanja na prostoru Jugoslavije tokom Drugog svetskog rata, pri čemu je ignorisana činjenica da posle Anšlusa 1938. godine Austrija nije postojala kao nezavisan državni entitet. Naglašavala se uloga visoko pozicioniranih Austrijanaca u Vermahtu, odnosno okupacionom aparatu u okupiranim delovima Jugoslavije, kao i veliki udeo Austrijanaca u ukupnom broju ratnih zločinaca registrovanih od strane Državne komisije za utvrđivanje zločina okupatora i njegovih pomagača. ${ }^{5} \mathrm{U}$ ovom segmentu propagandne kampanje protiv Alpske republike eksploatisani su i procesi u Beogradu i Ljubljani protiv visokih oficira Vermahta, odnosno nemačkog okupacionog aparata, održani 1947. godine. Jugoslovenska štampa iskoristila je činjenicu da je među optuženima bilo više Austrijanaca (Aleksandar Ler, Adalbert Lončar, Paul Gerhard, Fridrih Rajner, Helmut Glasder, Herman Doujak, Franc Hradecki, Valter Hohštajner, Leo Kus), pa su procesi u Beogradu i Ljubljani bili prilika za još jedno podvlačenje austrijske uloge $u$ Drugom svetskom ratu na jugoslovenskom prostoru. ${ }^{6}$

Pregovori diplomatskih predstavnika sila pobednica o austrijskom ugovoru 1947. godine u Londonu otvorili su mogućnost jugoslovenskom režimu da intenzivira diplomatsku borbu za Korušku. Slovenački diplomata Jože Vilfan zvanično je učesnicima konferencije u Londonu predstavio jugoslovenske zahteve prema Austriji. Radilo se o zahtevu za pripajanje 2470 $\mathrm{km}^{2}$ teritorije Koruške i $130 \mathrm{~km}^{2}$ u Štajerskoj. Jugoslaviji je na taj način trebalo da pripadnu Vilah, Velkermarkt, Blajburg i Klagenfurt. Jugoslovenska vlada je zatražila i poseban status za, kako se procenjivalo, 70.000 burgenlandskih Hrvata. Kao alternativa ovom rešenju statusa Hrvata u Austriji, predložena je razmena stanovništva, odnosno prelazak burganlandskih Hrvata u Jugoslaviju i istovremeno preseljenje Austrijanaca, koji bi se posle predložene izmene jugoslovensko-austrijske granice našli na jugoslovenskoj strani granice. Jugoslovenska vlada je u Londonu predstavila i svoje reparacione zahteve prema Austriji u visini od 150 miliona dolara. ${ }^{7}$

${ }^{4}$ Politika, 2. januar 1946; Politika, 25. januar 1946; Politika, 9. februar 1946; Politika, 19. decembar 1946; Borba, 8. januar 1946; Ljudska pravica, Politika, Borba, januar - mart 1947.

${ }^{5}$ Borba, 5. januar 1947; Ljudska pravica, 7. januar 1947.

${ }^{6}$ Politika, 6. februar 1947; Borba, 6. februar 1947; Politika, 14. februar 1947; Borba, 16. februar 1947; Ljudska pravica, 19. jul 1947.

${ }^{7}$ Gerald Schourz, Um Einheit und Freiheit. Staatsvertrag, Neutralität und das Ende der Ost-West-Besetzung Österreichs 1945-1955, Wien-Köln-Graz, 1998, 63-64; Politika, 25. januar 1947. 
Austrijska delegacija se na konferenciji u Londonu energično suprotstavila jugoslovenskim zahtevima. Savezni kancelar Leopold Figl, pozivajući se na plebiscit u Koruškoj 1920. godine, istakao je da su se koruški Slovenci tada nedvosmisleno izjasnili za Austriju. Jugoslovenske pretenzije na delove Štajerske prema austrijskom kancelaru nisu imale nikakvog etničkog opravdanja. ${ }^{8}$ Odbojno su na jugoslovenske zahteve reagovali i predstavnici zapadnih sila. Podrška jugoslovenskoj inicijativi došla je jedino od sovjetske diplomatije. Sovjetski delegat na konferenciji u Londonu je $u$ svom nastupu iskoristio jugoslovensku argumentaciju. Podvukao je austrijsku odgovornost za okupaciju Jugoslavije tokom Drugog svetskog rata i izneo kritiku na račun austrijske politike prema slovenačkoj manjini $u$ Koruškoj. ${ }^{9}$

Diplomatski rat za Korušku jugoslovenski režim je nastavio na konferenciji saveta ministara spoljnih poslova u Moskvi, održanoj od 10. marta do 24. maja 1947. Ovog puta jugoslovenske zahteve prema Austriji predstavio je Edvard Kardelj. Slovenački političar je oštro kritikovao austrijsku politiku prema slovenačkoj manjini u Koruškoj i podvukao austrijsku ulogu $\mathrm{u}$ okupaciji jugoslovenskog prostora tokom Drugog svetskog rata. ${ }^{10}$ Reakcija međunarodnih faktora na jugoslovenske zahteve bila je identična kao na konferenciji u Londonu. Dok su sovjetski predstavnici, Vjačeslav Molotov i Andrej Višinski, podržali jugoslovenske zahteve, šefovi diplomatije zapadnih sila na jugoslovensku inicijativu reagovali su, kao i ranije, negativno. ${ }^{11}$

Jugoslovenski režim, i pored zvaničnog neodustajanja od prvobitnih zahteva prema Austriji, očigledno je već u proleće 1947. godine postajao svestan nerealnosti postavljenih ciljeva. Otuda je jugoslovenski vrh iza zatvorenih vrata lobirao za znatno redukovane ciljeve. Edvard Kardelj je u pismu Višinskom od 20. aprila 1947. naveo tri umanjene verzije jugoslovenskih zahteva prema Austriji, pri čemu je ključni cilj Jugoslovena bio pokušaj kontrole dve austrijske hidrocentrale na Dravi - Žvabek i Labod. Prve dve verzije podrazumevale su manje granične korekcije $u$ oblasti pomenutih hidroelektrana, dok je treća verzija predviđala utvrđivanje „posebnih prava FNRJ u upravljanju tim centralama“ “ ${ }^{12} \mathrm{O}$ spremnosti da redukuju teritorijalne zahteve prema Austriji, jugoslovenske diplomate Aleš Bebler i Stanoje Simić su upoznali i britanskog ministra za civilno vazduhoplovstvo

${ }^{8}$ Isto, 69.

${ }^{9}$ Wiener Zeitung, 16. februar 1947.

${ }^{10}$ Arhiv Jugoslavije (AJ), Kabinet Maršala Jugoslavije (KMJ), 836, I-3-b/80, Izveštaj Tanjuga, Moskva 17. april 1947; Politika, 18. april 1947.

${ }^{11}$ Politika, 21. april 1947.

12 Jugoslovensko-sovjetski odnosi 1945-1956. Zbornik dokumenata, Beograd 2010, 487-493. 
Noela Bejkera. Britanski ministar je odbacio i ovu umanjenu verziju jugoslovenskih teritorijalnih zahteva. Umesto toga, on je jugoslovenskim diplomatama predložio sklapanje sporazuma sa Austrijom o eksploataciji dve pomenute hidrocentrale. ${ }^{13}$

Jugoslavija je aprila 1948. predstavila novu verziju korekcije jugoslovensko-austrijske granice. Radilo se o $680 \mathrm{~km}^{2}$ teritorije na granici prema Jugoslaviji. Osim toga, i dalje se insistiralo na reparacijama u iznosu od 150 miliona dolara. Kao i prethodne i ova jugoslovenska inicijativa završila se fijaskom, s obzirom na negativnu reakciju zapadnih diplomata. ${ }^{14}$

Sudbina jugoslovenskih pretenzija na delove Koruške rešena je dogovorom velikih sila na konferenciji ministara spoljnih poslova u Parizu, održanoj od 23. maja do 20. juna 1949. Preokret je nastupio nakon što je Sovjetski Savez odustao od podrške jugoslovenskim zahtevima. Andrej Višinski ocenio je zahteve jugoslovenske vlade opravdanim, ali je i podvukao da je nemoguće dalje odlaganje zaključenja austrijskog Državnog ugovora. ${ }^{15}$ Pariski kominike potvrdio je granice Austrije iz 1938. godine, ali i predvideo uključivanje u Državni ugovor garancija zaštite prava slovenačke i hrvatske manjine u Austriji. Dogovoreno je i da se od Austrije neće zahtevati plaćanje reparacija Jugoslaviji, ali je Jugoslaviji priznato pravo da „uzme, zadrži ili likvidira austrijsku imovinu, prava i interese na jugoslovenskoj teritoriji." 16

Odluka u Parizu izazvala je burne reakcije u Jugoslaviji. U zvaničnom odgovoru jugoslovenske vlade protestovano je protiv odluke saveta ministara spoljnih poslova, koja je ocenjena kao „velika nepravda“, suprotna „principima samoopredeljenja“: „Such an attitude and such inadequate decisions of the Council of Ministers of Foreign Affairs impose a great injustice upon an allied country which suffered heavy sacrifices in the war on the side of the anti-Hitler coalition; they are contrary to the principle of selfdetermination of peoples and of the responsibility for war crimes and devastations committed (...) ". ${ }^{17}$

I pored činjenice da jugoslovenski režim posle dogovora velikih sila u Parizu nije zvanično odustao od ranije iznetih zahteva prema Koruškoj, vlasti u Jugoslaviji su početkom 50-ih godina politiku prema Austriji počele

${ }^{13}$ Arnold Suppan, Die Kärntner Frage in den österreichisch-jugoslawischen Beziehungen 1945-1955, 412-414; Robert Knight, Die Kärntner Grenzfrage und der Kalte Krieg, u: Carinthia I, Jg. 175 (1985), 328-329.

${ }^{14}$ Wiener Zeitung, 4. maj 1948.

${ }^{15}$ Stourzh, Um Einheit und Freiheit, 150-151.

${ }^{16}$ Politika, 22. jun 1949.

${ }^{17}$ DAMIP, k-11, 1949, 411160, Nota Ministarstva spoljnih poslova FNRJ - Sjedinjenim Američkim Državama, 22. jun 1949; DAMIP, k-11, 1949, 411160, Nota Ministarstva spoljnih poslova FNRJ - vladi Sovjetskog Saveza, 22. jun 1949. 
da prilagođavaju novoj realnosti. Jugoslovenski režim posle Rezolucije Kominforma i ekskomunikacije iz Istočnog bloka više nije mogao da računa na sovjetsku podršku politici prema Austriji, što je postalo očigledno na konferenciji saveta ministara u Parizu. Osim toga, Jugoslavija je posle raskida sa Moskvom i satelitskim državama bila prinuđena da revidira spoljnopolitičku orijentaciju i započne oprezno približavanje Zapadu. To je uticalo i na promenu politike prema Austriji, odnosno postepeno i prećutno odustajanje od teritorijalnih i reparacionih zahteva prema toj zemlji. Izložena opasnosti od ulaska u izolaciju, posle sukoba sa Sovjetskim Savezom i moskovskim satelitima, Jugoslavija je izlaz videla u uspostavljanju veza sa zapadnim silama, što je svakako moralo da utiče i na opredeljenje da se smirivanjem tenzija u odnosu prema Austriji izbegne dalje proviciranje zapadnih sila, koje su se tada protivile narušavanju teritorijalnog integriteta Austrije. Takva promena politike prema Austriji omogućila je početak normalizacije jugoslovensko-austrijskih odnosa u prvoj polovini 50-ih godina.

Početak nove klime u odnosima Jugoslavije i Austrije ozvaničen je odlukom dve vlade o podizanju dotadašnjih privremenih političkih predstavništava Austrije u Jugoslaviji i Jugoslavije u Austriji na nivo poslanstava početkom 1951. godine. ${ }^{18}$ Jugoslovenska skupština je na sednici održanoj 16. januara 1951. zvanično okončala ratno stanje sa Austrijom. ${ }^{19}$

Početak normalizacije odnosa dve zemlje odrazio se i na izveštavanje jugoslovenske štampe o Austriji. Kampanju oštrih napada zamenili su objektivni i afirmativni tekstovi o Austriji. Pisano je o privrednom i kulturnom životu Austrije, a kritikovana je sovjetska okupacija dela Alpske republike. $^{20}$

Nova epoha austrijsko-jugoslovenskih odnosa obeležena je i susretima visokih funkcionera dve zemlje. Juna 1952. Jugoslaviju je posetio austrijski ministar spoljnih poslova Karl Gruber. Na sastanku Grubera i Josipa Broza na Brionima jugoslovenski lider je najavio oslobađanje austrijskih ratnih zarobljenika, koji su u Jugoslaviji bili osuđeni zbog ratnih zločina. Razgovarano je i o austrijskim dvovlasnicima, malograničnom prometu, a iskazana je i želja za intenziviranjem robne razmene između dve zemlje. ${ }^{21}$

U razgovoru sa austrijskim šefom diplomatije Tito je posebno naglasio privredni, ali i politički značaj saradnje sa Austrijom za Jugoslaviju, koja je tada bila izložena sovjetskom pritisku. Prema jugoslovenskom lideru,

${ }^{18}$ Wiener Zeitung, 31. januar 1951.

${ }^{19}$ DAMIP, k-6, 1951, Naši odnosi sa Austrijom; Die Presse, 20. januar 1951.

${ }^{20}$ Politika, 29. avgust 1951; Politika, 5. avgust 1951; Politika, 12. jul 1952; Borba, 14. oktobar 1951; Politika, 16. mart 1952.

${ }^{21}$ AJ, 836, I-2-a/9, Razgovor maršala Tita sa austrijskim ministrom Dr. Gruberom, Brioni, 23. jun 1952; Wiener Zeitung, 25. jun 1952. 
takva saradnja trebalo je da doprinese jačanju fronta protiv imperijalističkog pritiska sa Istoka. ${ }^{22}$

U zdravici povodom Gruberove posete Broz je podvukao neophodnost saradnje dve zemlje, a upadljivo je bilo njegovo minimiziranje preostalih, u zdravici nepomenutih, problema između Austrije i Jugoslavije. Pri tom je izostavljeno i, tokom prvih posleratnih godina, najspornije pitanje jugoslovensko-austrijskih odnosa - problem Koruške, odnosno problem statusa slovenačke manjine u Austriji: „Takve odnose i takvu saradnju mi smatramo neophodnom, jer je ona korisna za obje zemlje u svakom pogle$\mathrm{du}$, a naročito $u$ pogledu materijalne razmjene, što se već pokazalo u dosadašnjoj praksi (...) Smatram prema tome da će i ova posjeta gospodina ministra biti od znatne koristi baš u pogledu eliminisanja nekih preostalih, ne naročito značajnih elemenata, koji bi mogli smetati još većem produbljivanju saradnje i dobrih prijateljskih odnosa između naših naroda." ${ }^{23}$

Jačanje jugoslovensko-austrijskih odnosa nastavljeno je u narednoj godini. Ključni događaj u odnosima dve zemlje tokom 1953. bila je poseta Beču jugoslovenskog ministra spoljnih poslova Koče Popovića. Novembra te godine jugoslovenski šef diplomatije se sastao sa glavnim kreatorima austrijske politike: kancelarom Juliusom Rabom, ministrom spoljnih poslova Karlom Gruberom i austrijskim predsednikom Teodorom Kernerom. Prema zvaničnoj informaciji o sastanku Popovića sa Gruberom diskusija je protekla „u atmosferi uzajamnog razumevanja“, a navedeno je da je, uz ostalo, razgovarano o privrednoj saradnji Austrije i Jugoslavije, problemu austrijske imovine u Jugoslaviji i jugoslovenske imovine u Austriji. Poseta Popovića Beču, kako je ocenjeno, doprinela je „daljem produbljivanju prijateljskih odnosa" dve zemlje. Značajan rezultat posete jugoslovenskog ministra spoljnih poslova Beču bio je nastavak normalizacije diplomatskih odnosa Jugoslavije i Austrije, odnosno podizanje dotadašnjih poslanstava dve zemlje na nivo ambasada. ${ }^{24}$

Normalizaciju diplomatskih odnosa Jugoslavije i Austriji pratilo je i intenziviranje ekonomskih veza dve zemlje. Do jačanja trgovinske razmene došlo je posle zaključenja trgovinskog sporazuma između dve zemlje, avgusta 1948. Već u toku te godine robna razmena između Austrije i Jugoslavije višestruko je uvećena u odnosu na 1947. godinu. Tako je 1948. Austrija Jugoslaviji izvezla robe u vrednosti od 96,8 miliona šilinga (17 miliona - 1947. godine), dok je vrednost jugoslovenskog izvoza Austriji iznosila 122,5 mili-

${ }^{22}$ Arnold Suppan, Jugoslawien und der österreichische Staatsvertrag, u: Der österreichische Staatsvertrag 1955. Internationale Strategie, rechtliche Relevanz, nationale Identität, Wien 2005, 455.

${ }^{23}$ Tito, Govori i članci, 7, Zagreb 1959, 108-109.

${ }^{24}$ Wiener Zeitung, 12. novembar 1953. 
ona šilinga (25,9 miliona šilinga - 1947. godine) ${ }^{25}$ Vrhunac robne razmene Austrije i Jugoslavije u prvoj polovini 50-ih godina ostvaren je 1952. godine, kada je ukupan iznos razmene premašio milijardu šilinga. ${ }^{26}$

Trgovinska razmena između Jugoslavije i Austrije 1950-1955 (u milionima šilinga) ${ }^{27}$

\begin{tabular}{|l|r|r|r|r|r|r|}
\hline & 1950 & 1951 & 1952 & 1953 & 1954 & 1955 \\
\hline $\begin{array}{l}\text { Izvoz iz Jugoslavije } \\
\text { u Austriju }\end{array}$ & 214,5 & 341 & 618,6 & 247,6 & 439,4 & 386,2 \\
\hline $\begin{array}{l}\text { Izvoz iz Austrije } \\
\text { u Jugoslaviju }\end{array}$ & 262,1 & 287,6 & 557 & 544,1 & 633,5 & 558,2 \\
\hline
\end{tabular}

Austrija je u prvoj polovini 50-ih godina pripadala grupi najvažnijih spoljnotrgovinskih partnera Jugoslavije, uz SR Nemačku, Sjedinjene Američke Države, Italiju i Veliku Britaniju. Udeo trgovanja sa Austrijom tokom 1950. i 1952. godine premašio je $10 \%$, dok je udeo razmene sa Austrijom u jugoslovenskom uvozu tokom perioda 1950-1955. bio najveći 1950. godine i iznosio je $7,4 \%{ }^{28}$

Jugoslavija je za Austriju predstavljala manje značajnog trgovinskog partnera. U pomenutom periodu udeo trgovinske razmene sa Jugoslavijom u ukupnoj vrednosti austrijske spoljne trgovine bio je najveći 1952. godine $(4,4 \% \mathrm{u}$ uvozu, $5,2 \%$ u ukupnom austrijskom izvozu $){ }^{29}$

${ }^{25}$ Österreichisches Statistisches Zentralamt, Statistik des Außenhandels Österreichs 1947; Österreichisches Statistisches Zentralamt, Statistik des Außenhandels Österreichs 1948; Jugoslavija 1918-1988. Statistički godišnjak, Beograd 1989.

${ }_{26}$ Österreichisches Statistisches Zentralamt, Statistik des Außenhandels Österreichs 1948, 1949, 1950, 1951, 1952, 1953, 1954, 1955; DAMIP, k-4, 1953, 43932, Opšti problemi naše trgovinske razmene sa Austrijom.

27 Österreichisches Statistisches Zentralamt, Statistik des Außenhandels Österreichs 1948, 1949, 1950, 1951, 1952, 1953, 1954, 1955.

${ }^{28}$ Jugoslavija 1918-1988. Statistički godišnjak.

${ }^{29}$ Österreichisches Statistisches Zentralamt, Statistik des Außenhandels Österreichs 1948, 1949, 1950, 1951, 1952, 1953, 1954, 1955. 
Jugoslovenski udeo u spoljnoj trgovini Austrije
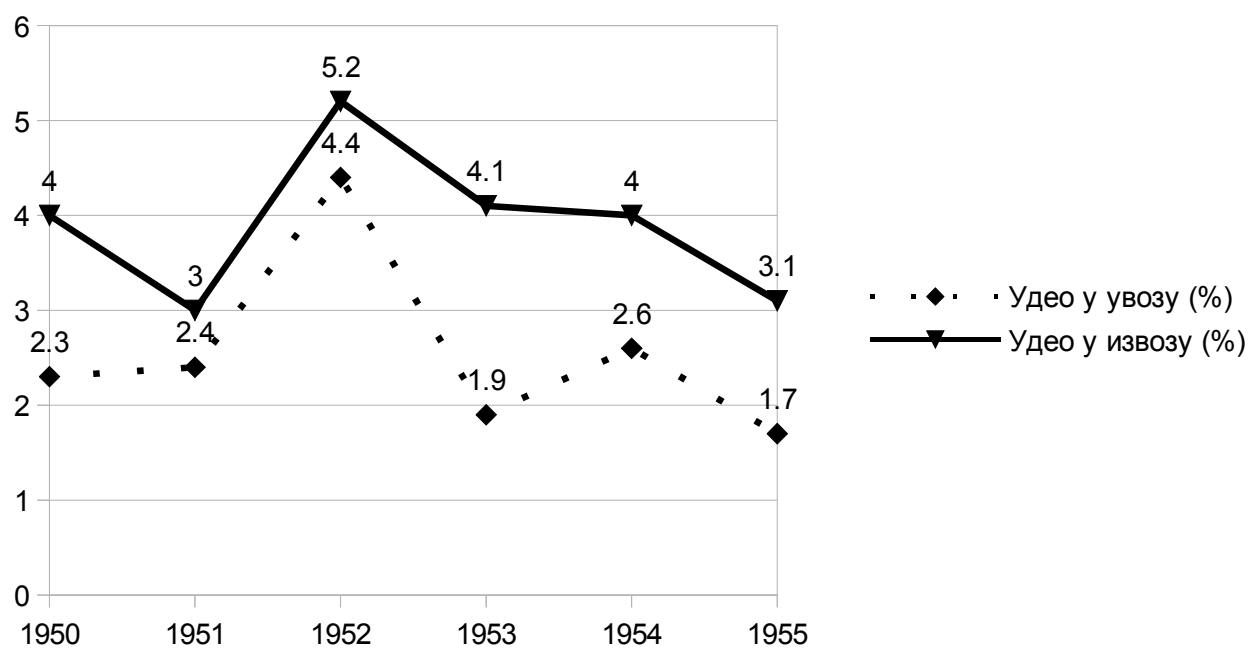

Austrijski udeo u spoljnoj trgovini Jugoslavije

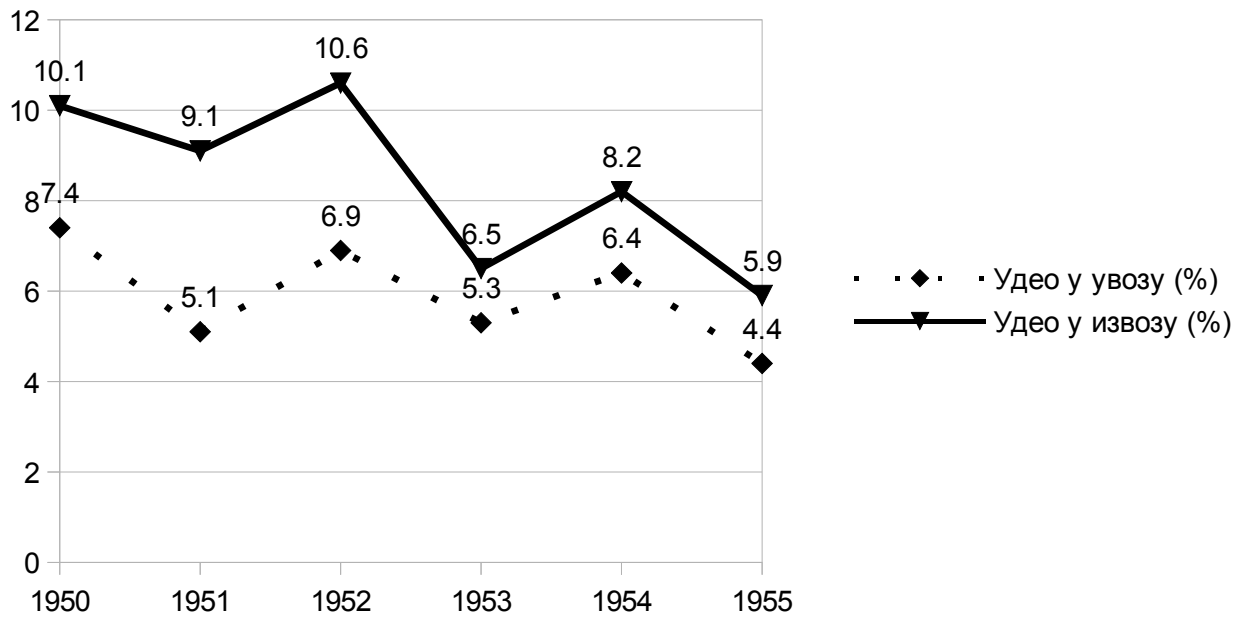

Normalizaciju jugoslovensko-austrijskih odnosa tokom prve polovine 50-ih godina pratilo je stalno jačanje interesovanja austrijskih turista za turističke destinacije u Jugoslaviji, a pre svega na jadranskom primorju. Tako je 1951. u Jugoslaviji boravilo 13.000 turista iz Austrije, dok je na kraju analiziranog perioda, 1955. godine, Jugoslaviju posetilo više od 70.000

\footnotetext{
${ }^{30}$ Isto.

${ }^{31}$ Jugoslavija 1918-1988. Statistički godišnjak, Beograd 1989.
} 
austrijskih turista, što je činilo 15\% ukupnog broja stranih turista koji su te godine posetili Jugoslaviju. Tokom 1951. i 1952. godine Austrijanci su predstavljali najbrojniju grupu stranih turista u Jugoslaviji. ${ }^{32}$

Austrijski turisti u Jugoslaviji 1950-1955

\begin{tabular}{|l|r|r|}
\hline & $\begin{array}{c}\text { Ukupan broj austrijskih turista } \\
\text { u Jugoslaviji }\end{array}$ & $\begin{array}{c}\text { Udeo u ukupnom broju } \\
\text { stranih turista (\%) }\end{array}$ \\
\hline 1950 & 2.100 & 5,1 \\
\hline 1951 & 12.900 & 18,3 \\
\hline 1952 & 25.400 & 19,7 \\
\hline 1953 & 44.000 & 18 \\
\hline 1954 & 51.100 & 15,9 \\
\hline 1955 & 73.900 & 15,2 \\
\hline
\end{tabular}

Pokazatelj nove klime $\mathrm{u}$ odnosima Jugoslavije i Austrije u prvoj polovini 50-ih godina bila je i jugoslovenska podrška zaključivanju austrijskog Državnog ugovora. U pozdravnom govoru prilikom posete Karla Grubera Jugoslaviji, juna 1952, Josip Broz Tito je podvukao „moralnu i politič$\mathrm{ku}$ " podršku Austriji u vezi sa pitanjem Državnog ugovora. ${ }^{34}$ Postoje izvori koji potvrđuju da je jugoslovenska diplomatija 1954. godine nastojala da ubedi Sovjete u potrebu zaključivanja austrijskog Državnog ugovora. ${ }^{35}$ Dostupni izvori ukazuju da je jugoslovenski režim bio zainteresovan za uspostavljanje nezavisne Austrije s obzirom na očekivane pozitivne efekte takve promene na bezbednost Jugoslavije. Početkom 50-ih godina vlasti $\mathrm{u}$ Jugoslaviji su priželjkivale zaključivanje Državnog ugovora i sa tim povezano povlačenje sovjetskih trupa iz Austrije, budući da bi to, kako se mislilo, oslabilo sovjetski pritisak na Jugoslaviju. ${ }^{36}$

\footnotetext{
${ }^{32}$ Isto.

${ }^{33}$ Isto.

${ }^{34}$ Die Presse, 24. juni 1952.
}

${ }^{35}$ Arnold Suppan, Jugoslawien und der österreichische Staatsvertrag, u: Der österreichische Staatsvertrag 1955. Internationale Strategie, rechtliche Relevanz, nationale Identität Wien 2005, 462-463.

${ }^{36}$ ÖstA/AdR, BmfaA, II-Pol, GZl. 120.888/pol50, Der politische Vertreter der Republik Österreich in Jugoslawien an den Bundesminister für die auswärtigen Angelegenheiten, 4. januar 1950; ÖstA/AdR, BmfaA, II-Pol, GZl. 323.053/pol53, Der Gesandte der Republik Österreich in Jugoslawien an den Bundesminister für die auswärtigen Angelegenheiten, 29. Juni 1953; AJ, 836, I-a/9, Materijal o aktuelnom položaju Austrije i austrijsko-jugoslovenskim odnosima. 
Austrijski državni ugovor, potpisan 15. maja 1955. u dvorcu Belvedere, regulisao je sporna pitanja jugoslovensko-austrijskih odnosa. U članu 7 Državnog ugovora definisana su prava pripadnika slovenačke i hrvatske manjine u Austriji, dok je članom 27 Jugoslaviji priznato pravo na austrijsku imovinu na tlu Jugoslavije. ${ }^{37}$ Potpisivanje austrijskog Državnog ugovora izazvalo je pozitivne reakcije u Jugoslaviji. Na stranicama beogradskog dnevnika Borba podvučena je nada da će potpisivanje Državnog ugovora doprineti miru u svetu. Na važnu vest iz Beča reagovao je i Josip Broz Tito, koji je izrazio zadovoljstvo što je ovo pitanje „koje je mučilo svijet ... skinuto s dnevnog reda". ${ }^{38}$

Odnosi Jugoslavije i Austrije posle potpisivanja austrijskog Državnog ugovora, 1955. godine, nisu postali idilični. Jugoslavija je često kritikovala austrijsku politiku prema tamošnjim jugoslovenskim manjinama (Slovencima i gradišćanskim Hrvatima), pa su jugoslovensko-austrijski odnosi i $\mathrm{u}$ narednom periodu prolazili kroz stalna iskušenja. Pojavljivale su se, međutim, i nove spone između dve zemlje, poput useljavanja desetina hiljada jugoslovenskih ekonomskih migranata u Austriju ili rastućeg interesovanja austrijskih turista za letnji odmor na jadranskoj obali.

${ }^{37}$ Stourzh, Um Einheit und Freiheit, 689-690, 742-743. - Član 7 austrijskog Državnog ugovora, koji se ticao prava jugoslovenskih etničkih manjina u Austriji (Slovenaca i gradišćanskih/burgenlandskih Hrvata), sadržao je sledeće stavke: 1. Österreichische Staatsangehörige der slowenischen und kroatischen Minderheit in Kärnten, Burgenland und der Steiermark genießen dieselben Rechte auf Grund gleicher Bedingungen wie alle anderen österreichischen Staatsangehörigen einschließlich des Rechtes auf ihre eigenen Organisationen, Versammlungen und Presse in ihrer eigenen Sprache; 2. Sie haben Anspruch auf Elementarunterricht in slowenischer und kroatischer Sprache und auf eine verhältnismäßige Anzahl eigener Mittelschulen; in diesem Zusammenhang werden Schullehrpläne überprüft und eine Abteilung der Schulaufsichtsbehörde wird für slowenische und kroatische Sprache errichtet werden; 3. In den Verwaltungs-und Gerichtsbezirken Kärntens, des Burgenlandes und der Steiermark mit slowenischer, kroatischer oder gemischter Bevölkerung wird die slowenische oder kroatische Sprache zusätzlich zum Deutschen als Amtssprache zugelassen. In solchen Bezirken werden die Bezeichnungen und Aufschriften in slowenischer oder kroatischer Sprache verfasst; 4. Österreichische Staatsangehörige der slowenischen und kroatischen Minderheit in Kärnten, Burgenland und der Steiermark nehmen an den kulturellen, Verwaltungs-undGerichtseinrichtungen in diesen Gebieten auf Grund gleicher Bedingungen wie andere österreichische Staatsangehörige teil, 5. Die Tätigkeit von Organisationen, die darauf abzielen, der kroatischen oder slowenischen Bevölkerung ihre Eigenschaft und ihre Rechte als Minderheit zu nehmen, ist zu verbieten.

${ }^{38}$ Josip Broz Tito, Govori i članci, 10, Zagreb 1959, 172; Suppan, Jugoslawien und der österreichische Staatsvertrag, 471. 
Petar Dragišić

THE YUGOSLAVIA AND AUSTRIA 1945-1955

Summary of Relations

\section{Summary}

The article provied brief overview of the relations between the Yugoslavia and Austria in the firs post Wolrd War Two decade. Those relations were focused on the political problem of belonging of the teritory of Koruska-Karnten which distrupted the relations between the two states. The Tito's Yugoslavia launched strong international campaign agianst the Austria in aim to reach the control over the province mostly inhabitend with the Sloveenians. But this policy failed in late 1940-ties. Later, after the Yugoslav leaving the pro-Soviet bloc, in 1949, the process of normalisation was vivid in the mutual relations. The diplomatic representatives were exchanged, and in 1952, the Austrian foreign minsiter Gruber visited Yugoslavia and met the president Tito. In this period the cultural and economical ties were establisihed. This improvement also changed the mutual perception on both sides in the beginning of the 1950-ties. It lead to rise of the interest among Austrians for the turism in Yugoslavia. Still, after 1955, the question of the Slovene minority in Austria remained the problematical issue in the relations between two states. 